\title{
From Genuineness to Finder Authenticity in Communicative Language Teaching
}

\author{
Mehran Esfandiari $^{1} \&$ Mir Wais Gawhary ${ }^{1}$ \\ ${ }^{1}$ Defense Language Institute Foreign Language Center, Monterey, California, The United States of America \\ Correspondence: Mehran Esfandiari, Defense Language Institute Foreign Language Center, Monterey, California, The \\ United States of America.
}

Received: March 19, 2019 Accepted: April 8, 2019 Online Published: April 16, 2019

doi:10.11114/ijecs.v2i1.4149 URL: https://doi.org/10.11114/ijecs.v2i1.4149

\begin{abstract}
The shift from traditional towards more learner-centered approaches to teaching has resulted in the concept of authenticity becoming central to Communicative Language Teaching (CLT). As a relational notion, authenticity has to do with the interaction between learners and input materials in terms of appropriate responses, as opposed to its notion of genuineness as an absolute quality. It paves the way for language to be authenticated through context, as it encourages a use-to-learn rather than a learn-to-use approach. Using authentic materials requires a great deal of attention to be paid to not only the contextualization and authenticity of tasks, but also to the incorporation of genuine texts into task design, which itself has been revolutionized through modern technology. Using the Web as a technological tool has resulted in another version of authenticity, which might be in line with finder authenticity. The main aim of this paper is to argue that the notion of authenticity has come a long way from genuineness to finder authenticity.
\end{abstract}

Keywords: authenticity, CLT, learner-centered approaches, technology, autonomy

\section{Introduction}

Following the shift from traditional towards more learner-centered approaches to teaching English, the concept of authenticity has become central, particularly to CLT, so much so that there has been a growing interest in the use of authentic materials in the field of English Language Teaching (ELT). Traditional approaches would facilitate easy acquisition by presenting simplified language to learners; however, there is a growing tendency to present authentic language - that is, language in real-life situations (Widdowson, 1990). This is because they are real-life texts that contain real language, and they are written for native speakers, not for pedagogic purposes (Wallace, 1992). Indeed, reality is imported into classrooms, and that gives learners the opportunity to benefit from exposure to the same language as native speakers (Guariento \& Morley, 2001). Therefore, it is argued that authentic materials can help learners to not only build up confidence, but also to grapple with various issues in the target language in the outside world more effectively.

Contrary to the notion of genuineness as an absolute quality, authenticity refers to the interaction between learners and input materials in terms of suitable responses, so it is considered a relational notion. Instead of studying about English in order to learn it, learners study in English to acquire it. This makes it easier for their language to be authenticated through context. However, when it comes to using authentic materials, attention has to be drawn to contextualization and the authenticity of tasks, and value has to be attached to the incorporation of genuine texts into task design. Interestingly, modern technology has revolutionized such incorporation. Thanks to advances in technology, particularly the Internet, these days students have unlimited access to a broad range of online authentic materials, and their purposeful action can develop in a wider community. Such use of the Web as a technological tool has led to another version of authenticity that might be in line with finder authenticity. The main aim of this paper is to argue that the notion of authenticity has come a long way from genuineness to finder authenticity.

\section{What Is Authenticity?}

When looked up in dictionaries, the word authenticity is defined as the quality of being genuine, real, and natural. However, defining authenticity is not a straightforward task where ELT is concerned. In the past, studies on authenticity were restricted to the discussion of texts (Swaffar, 1985); in applied linguistics, it can trace its origins back to the mid 1960s when concerns were raised over language learners' exposure to texts that were not representing the target 
language they were trying to learn (Wong et al., 1995). Indeed, "authenticity at the time was seen as a simple notion distinguishing texts extracted from real-life sources from those written for pedagogical purposes" (Lewkowicz, 2000, p. 45). A text was considered authentic provided that it had been "created to fulfill some social purpose in the language community in which it was produced" (Little, Devitt, \& Singleton, 1989, p. 25). Simply stated, authentic texts contained real language, and they were written for native speakers, not for language learners (Nunan, 1988; Wallace, 1992; Lee, 1995; Peacock, 1997). Therefore, it can be suggested that authentic texts are designed for real-life communicative rather than language teaching purposes.

It was in the late 1970s that authenticity was revisited. Not only was a debate initiated over its nature, but a movement was also launched towards its notion. The first step was taken by Widdowson, who drew a distinction between genuineness and authenticity, to assert that there is a difference between language instances - that is, texts, and the way they are put into a certain context. He argued that "genuineness is a characteristic of the passage itself and is an absolute quality, authenticity is a characteristic of the relationship between the passage and the reader and it has to do with appropriate response" (Widdowson, 1978, p. 80). Indeed, by attaching significance to the interaction between the audience and the text, attention has to be drawn to the nature of the outcome that starts developing out of textual input (Widdowson, 1990). That is to say, what we characterize as authentic should be the relationship between the learner and the input text and the learner's response to that. Thus, "authenticity lies in the nature of the interaction between the reader (or hearer) and the text” (Dudley-Evans \& St. John, 1998, p. 28).

It is important to note that authenticity is different from the selection of genuine texts (van Lier, 1996). Authentic materials have the potential to appear unauthentic to learners and vice versa. In practice, however, the extent to which they seem authentic to learners is heavily dependent on the way they are presented to them. Lee (1995) puts forward the term learner authenticity to refer to the interaction between learners and input materials in terms of suitable responses. Contrary to the notion of genuineness as an absolute quality, such a viewpoint takes authenticity into account as a relational notion that is developed by the learner. Indeed, "the notion of authenticity itself has become increasingly relative, being increasingly related to specific learner needs [and context] and less and less concerned with the authentic nature of the input materials themselves" (Clarke, 1989, p. 36). In other words, authenticity is more and more concerned with the psychological make-up of learners as well as their world of experience rather than genuineness of texts (Amor, 2002; Fiske \& Hartley, 2003). Consequently, it can be argued that through social interaction and use of language, we create our own sense of authenticity.

\section{Authenticity in Language Learning}

Contrary to traditional approaches that facilitate easy acquisition by presenting simplified language to learners, there has been a growing tendency to present authentic language, so much so that the shift towards the communicative movement has resulted in the concept of authenticity becoming central to CLT. This is because reality can be imported into classrooms and learners benefit from exposure to the same language as native speakers (Dudley-Evan \& St John, 1998; Douglas, 2000; Mishan, 2005; Harding, 2007). There is a general consensus on the significant role that natural exposure can play in not only creating a communicative language environment, but also in paving the way for the process of language acquisition (Guariento \& Morley, 2001). It is argued that processing input enables learners to understand the target language, as opposed to production which only provides them with an opportunity to practice what they have already learnt (Skehan, 1998).

Cognitive theories of language acquisition lay great emphasis on the importance of practicing the target language within the context of its real operating conditions (Johnson, 1988). Indeed, "the more authentically the classroom mirrors the real world, the more real the rehearsal will be and the better the learning and transfer will be" (Arnold, 1991, p. 237). Thus, there is a need to offer a chance to learners to practice the target language under the same conditions that apply to real-life situations (Ellis, 2003). Authentic materials provide "the essential predications of language proficiency" (Swaffar, 1985, p. 17); they present comprehensible input - which is linguistically authentic - in a way that makes it possible for learners to "practice decoding message systems rather than individual words" (Swaffar, 1985, p. 17). Therefore, language use can be authenticated through context (van Lier, 1988), as learners will become more acquainted with certain ways of using the target language to perform different functions in the real world.

It is inevitable that such an essence can be captured best by the term authenticity as a connection between the classroom and the outside world (McGrarry, 1995). It should be mentioned that "the ultimate purpose should be authentic communication between the text (oral or written) and its recipient as a result of the interpretation brought to the text by the latter" (Canado \& Esteban, 2005, p. 1). Thus, as some kind of natural exposure, authenticity can act as a link between CLT and second language acquisition (SLA) by encouraging a use-to-learn approach to language learning. That is to say, instead of learning to use the language, learners use the language to learn it.

Having believed in authenticity as a relative rather than an absolute quality, Breen (1985) puts forward the idea of 
multiple authenticities by making a list of four types of authenticity as: texts to be used with students as input data, students' own perception of texts, tasks developed from materials, and the social context of the language classroom. Taking into account the continual interrelationship among the four authenticity types, three pedagogical proposals are made. Firstly, any source of data that comes to the assistance of learners by facilitating an authentic interpretation can be considered an authentic text. It is argued that such a text can enable learners to "discover those conventions of communication in the target language which will enable him or her to gradually come to interpret meaning within the text in ways likely to be shared with fluent users of the language" (Breen, 1985, p. 68). Secondly, language learning tasks can be classified as authentic provided that they call for not only genuine communication during learning, but also for meta-communication about learning. And thirdly, as a social context with the aim of language learning, the language classroom can play an authentic role in creating "conditions in which the participants can publicly share the problems, achievements and overall process of learning a language together as a socially motivated and socially sustained activity" (Breen, 1985, p. 68). However, it can be argued that most of the time the type of authenticity that is being dealt with cannot be clear enough and that a great deal of attention has been paid to authenticity as a quality of realness rather than a product of interactions (Cooper, 1983).

\section{Is Authenticity Good?}

When it comes to the learning process, using authentic materials in language classes has always been the subject of heated debate. Indeed, there have been arguments to justify whether or not they can be beneficial to language learners. Those who advocate the use of authentic materials attach value to the language that is natural, and therefore to a familiarity with fundamental characteristics of real-life instances. They argue that language used outside the classroom may not be reflected in non-authentic materials. Thus, it can be asserted that the direct connection of authentic materials with real-life experiences can help to not only develop, but also to ensure meaningful interaction, which itself is a pre-requisite for the development of communicative and strategic competence (Nunan, 1994; Merriam \& Caffarella, 1999; Perreault, 1999; Tomlinson, 2003). Thus, such materials result in learners getting a genuine feel for not only the language, but also for the situations.

It should also be emphasized that authentic materials are recognized by learners "as pertaining to the professional community to which they aspire" (Mishan, 2005, p. 26). They have the potential to furnish learners with incidental information on certain cultural aspects, which are normally filtered out of specifically designed materials (Amor, 2002). As a result, they can be interesting and enjoyable as well as encouraging and motivating because they prove language use in real-life situations to students (Clarke, 1989; Nuttall, 1996; Guariento \& Morley, 2001). In addition, since they give students the chance to arrive at meaning by using non-linguistic clues, they can assist learners to build up confidence and concentration. Therefore, they will be capable of grappling with various issues in the target language in the outside world more effectively (Nunan, 1994; Peacock, 1997; Guariento \& Morley, 2001).

On the other hand, where using authentic materials in language classes is concerned, some teaching professionals have drawn attention to a number of negative aspects. Sometimes unnecessary vocabulary items as well as complicated structures of the language are included in authentic materials (Richards, 2001); they can cause difficulties and lead to confusion. Indeed, it can be argued that if the wrong type of text is selected, it can pose a big problem for learners and result in the opposite effect by de-motivating them. Furthermore, it is important to note that sometimes it can be quite challenging to find a proper level of text for a group (Wardman, 2009). Thus, low level students might have trouble understanding authentic materials, get confused, and feel frustrated.

However, it might be argued that such drawbacks can be overcome provided that the materials are appropriately graded for learners at different levels. When it comes to the use of authentic materials in language classes, more contextualization and sensitivity are required. Accordingly, in order for authentic materials to be effective and motivating, the question is not whether they should be used or not; instead, the question is when and how they should be used (Guariento \& Morley, 2001).

\section{Authentic Tasks}

There has been a shift in the main focus of studies from the authenticity of texts towards that of tasks. It is interesting to note that "the narrow concern with text authenticity that characterized the early years of the communicative movement has since given way to a concern for the nature of tasks" (McGrath, 2002, p. 12). This is because authenticity has to do with the learner's involvement with the task. Indeed, it is argued that "a pedagogical paradigm that has been increasingly associated with [authenticity] is the task" and "the marriage of the authentic text and the task model is a felicitous one, in that both derive from the real-world" (Mishan, 2005, p. 67). Therefore, drawing a clear distinction between tasks and exercises is of paramount importance.

Contrary to exercises, which are activities that require the form-focused use of language, tasks are considered the ones that call for its meaning-focused use. Such a distinction can result in participants taking a markedly different role. 
Where exercises are concerned, they are required to act mainly as learners. On the other hand, when it comes to dealing with tasks, their primary function is to act as language users. This is largely because they are expected to employ communicative processes of real-world language use (Ellis, 2003). Furthermore, it is important to make a distinction between the two task types known as authentic communication and language learning tasks. An authentic communication task is one that "expects an authentic communicative response or authentic language-using behavior on the part of the learner" (Breen, 1985, p. 65). Simply stated, learners are involved in some kind of communication that facilitates the rehearsal of real-life target tasks. An authentic language learning task, on the other hand, is one that draws the learner's attention to the form.

There is a general consensus that authentic activities have certain characteristics. Authentic tasks are the ones that are related to the real world, are challenging because the purpose is not always clearly defined, are seamlessly integrated with assessment, create opportunities for collaboration, provide chances of reflection, and encourage competing remedies (Herrington, Oliver, \& Reeves, 2003). They also have the potential to facilitate some group work in which students' roles might bear a striking resemblance to those of people in the real world. This can provide significant chances of interaction, communication, and even negotiation. Therefore, as a result of collaboration, language learners can learn the concepts under discussion (Jaworski, 1994).

It should be mentioned that particular attention needs to be paid to a combination of genuineness and authenticity within the context of task design. This is because the context can play a major role in authenticating tasks for language learners. It is argued that such authenticity can be improved by incorporating genuine materials in task design as input data (Amor, 2002). In doing so, great emphasis needs to be placed on "provenance and authorship of the text", "original communicative and socio-cultural purpose of the text", "original context (e.g. its source, socio-cultural context) of the text", "learning activity engendered by the text", and "learner's perceptions of and attitudes to the text and the activity pertaining to it" (Mishan, 2005, p. 18). Thus, in order for learners to be exposed to real language, value has to be given to the incorporation of genuine texts into task design. Interestingly, such incorporation has been revolutionized by advances in technology.

\section{Authenticity and Information and Communications Technology (ICT)}

The shift from traditional towards more communicative approaches to language learning and teaching has resulted in the idea of learner-centeredness being brought to the fore. There is a general consensus that significance has to be attached to using authentic materials in language pedagogy as standard practice. Where authenticity in language learning is concerned, great emphasis has to be laid on the role that ICT can play (Kukulska-Hume, 2009). This is because it creates enormous opportunities for language learners to have unlimited access to a broad range of authentic texts from the target culture. Indeed, "as ICT becomes increasingly part of our daily reality, the dichotomy between real life and the classroom, which theorists struggled to resolve during the authenticity debate, is becoming something of an anachronism. Given access to the technology, today's learners can reach out and touch real life at the tap of the keyboard. The physical properties of the electronic medium and the students' engagement with it are thus causing a paradigm shift in our conception of authenticity" (Mishan, 2005, p. 19).

Where using ICT in language learning is concerned, it is inevitable that those devices and activities that are used bear a striking resemblance to those of our daily life (Kenning, 2007). However, it is important to draw a distinction between the use of the World Wide Web as a resource and its use as a medium. When it is used as a resource, the genuine materials it can offer might fall into three main categories as follows:

- The ones that are copied onto the Internet without being originally produced for online purposes. It should be mentioned that such materials, for instance books, are often transferred to the Web in the form of an abridged version.

- The ones which are adapted for the Internet without being initially produced for the online environment. It is interesting to note that the vast majority of such materials, for example newspapers, are available in the form of not only online, but also hard copy versions.

- The ones that are specifically produced for online purposes. For instance, financial institutions and government websites.

When the World Wide Web is used as a medium, on the other hand, it paves the way for access to a wide variety of websites, which are specifically designed for language learning purposes. It should be emphasized that within such a context, it creates opportunities for language to be practiced through interactive exercises as well as activities (Mishan, 2005).

Taking the above classifications into consideration, weight has to be attached to using ICT in language learning since such a resource aspect has revolutionized materials preparation. It saves teachers regular trips to various locations on 
their authentic texts search. Indeed, teachers can set tasks for learners to work with the chosen texts on the Internet. In addition, attention needs to be drawn to the currency of the Internet as another aspect that proves its usefulness as a resource for language learning. "The currency of the Web quite simply outranks that of any other medium. The up-to-dateness of the information it carries and of the language it uses, its capacity to cater minutely to personal needs and interests thanks to powerful search capabilities, and not least, the transferable electronic literacy skills required to use it, all give the Web an immediacy and relevance that galvanizes students using it in their language learning" (Mishan, 2005, p. 245).

As can be seen, ICT has the potential to act as not only a source of genuineness, but also as a useful resource for language learning. It should be emphasized that in light of its personal use, incidental learning can take place. Moreover, as a result of concentrating their efforts on dealing with complicated interactions, learners will be capable of producing language beyond their mastery of the English language (Coniam \& Wong, 2004). Therefore, it can be argued that ICT, and particularly online sources, can facilitate some kind of autonomous learning.

\section{ICT and Finder Authenticity}

Over the past few decades, a great deal of attention has been paid to learner autonomy from various angles, so much so that acquiring autonomous learning techniques as a life skill has appeared to be appealing. Where language learning is concerned, modern technology seems to have substantial implications for learner autonomy. Indeed, "the radical effect of ICT has stimulated an overt shifting of responsibility for learning from the teacher to the learner and thereby reaffirming the long association between technology and autonomy" (Mishan, 2005, p. 241). Interestingly, thanks to the World Wide Web, learners' purposeful action has started developing in a wider community on the Internet (Potts, 2005). To put it another way, they intend to achieve something useful as a result of reaching a wider community on the Web.

It can be argued that using the Web for language learning can be taken into account as a version of authenticity. Students can benefit from electronic literacy, which enables them to not only find and choose, but also to classify and use information. It should also be mentioned that critical reflection on choices and decisions can be considered the most pertinent responsibility. As can be seen, such authenticity might be in line with activities that require learners to go out, find texts, and bring them to the classroom (van Lier, 1996), which can be taken into consideration as a crucial aspect of autonomy, as these are learners who opt for the texts, not the teacher. Therefore, it can be argued that such authenticity might be referred to as finder authenticity.

\section{Conclusion}

The shift towards the communicative movement has resulted in the concept of authenticity becoming central to CLT. Contrary to the notion of genuineness as an absolute quality, authenticity is considered a relational notion, which refers to the interaction between learners and input materials in terms of suitable responses. Processing input enables learners to understand the target language more effectively, so in order for their language use to be authenticated through context, there is a need to give them the opportunity to practice the target language under the same conditions that apply to real-life situations. Not only does authenticity lead to a connection between the classroom and outside world, but it also doubles as some kind of natural exposure. Therefore, it has the potential to act as a link between CLT and SLA by encouraging a use-to-learn approach to language learning.

Where using authentic materials is concerned, more contextualization and sensitivity are required, and a great deal of attention has to be paid to the authenticity of tasks. In order for learners to be exposed to real language, significance has to be attached to the incorporation of genuine texts into task design. Such incorporation has been revolutionized through advances in technology. ICT can create opportunities for language learners to have unlimited access to a wide range of authentic texts. It can act as not only a source of genuineness, but also as a useful resource for language learning. Its personal use can result in incidental learning - that is, learners will be able to produce language beyond their mastery of the English language. Thus, ICT, particularly online sources, can pave the way for autonomous learning.

When it comes to language learning, modern technology appears to have substantial implications for learner autonomy. Thanks to the Internet, learners' purposeful action has begun to develop in a wider community on the Web. Using the Web for language learning might be compared to activities that require learners to go out, lay their hands on texts, and bring them to the classroom. Since these are learners who decide on the texts, not the teacher, it can be argued that such Web use might be in line with finder authenticity. 


\section{References}

Amor, S. (2002). Authenticity and Authentication in Language Learning. Bern, Switzerland: Peter Lang D. Retrieved Mar 3, 2019, from https://www.peterlang.com/view/title/30840

Arnold, E. (1991). Authenticity revisited: How real is real? English for Specific Purposes 10(3), 237-244. https://doi.org/10.1016/0889-4906(91)90027-T

Breen, M. P. (1985). Authenticity in the language classroom. Applied Linguistics, 6(1), 60-70. https://doi.org/10.1093/applin/6.1.60

Canado, M., \& Esteban, A. (2005). Authenticity in the teaching of ESP: An evaluation proposal. Scripta Manent, 1(1) 35-43. Retrieved from http://ww.sdutsj.edus.si/ScriptaManent/2005_1/Perez_Almagro.pdf.

Clarke, D. F. (1989). Communicative theory and its influence on materials production. Language Teaching 22(2), 73-86. https://doi.org/10.1017/S0261444800014592

Coniam,D., \& Wong, R. (2004). Internet relay chat as a tool in the autonomous development of ESL learners' English language ability: An exploratory study. System, 32, 321-335. https://doi.org/10.1016/j.system.2004.03.001

Cooper, D. E. (1983b). Authenticity and learning: Nietzsche's educational philosophy. London: Routledge \& Kegan Paul.

Douglas, D. (2000). Assessing language for specific purposes. Cambridge: Cambridge University Press.

Dudley-Evans, T., \& St John, M. J. (1998). Developments in English for specific purposes: A multidisciplinary approach. Cambridge: Cambridge University Press.

Ellis, R. (2003). Task-based language learning and teaching. Oxford: Oxford University Press.

Fiske, J., \& Hartley, J. (2003). Reading television. London: Routledge.

Guariento, W., \& Morley, J. (2001). Text and task authenticity in the EFL classroom. ELT Journal, 55(4), 347-353. https://doi.org/10.1093/elt/55.4.347

Harding, K. (2007). English for Specific purposes. Oxford: Oxford University Press.

Herrington, J., Oliver, R., \& Reeves, T. C. (2003). Patterns of engagement in authentic online learning environment. Australian Journal of Educational Technology, 19(1), 59-71. https://doi.org/10.14742/ajet.1701

Jaworski, B. (1994). Investigating mathematics teaching: A constructivist enquiry. London: Falmer Press.

Johnson, K. (1988). Mistake correction. ELT Journal, 42, 89-101. https://doi.org/10.1093/elt/42.2.89

Kenning, M. M. (2007). ICT and language learning. From print to the mobile phone. Basingstoke, UK: Palgrave Macmillan. https://doi.org/10.1057/9780230591325

Kukulska-Hulme, A. (2009). Will mobile learning change language learning? ReCALL, 21(2), 157-165. https://doi.org/10.1017/S0958344009000202

Lee, W. (1995). Authenticity revisited: Text authenticity and learner authenticity. ELT Journal, 49(4), 323-328. https://doi.org/10.1093/elt/49.4.323

Lewkowicz, J. A. (2000). Authenticity in language testing: Some outstanding questions. Language Testing 17, 43-64. https://doi.org/10.1177/026553220001700102

Little, D., Devitt, S., \& Singleton, D. (1989). Learning Foreign Languages from Authentic Texts: Theory and practice. Dublin: Authentik Language Learning Resources Ltd.

McGarry, D. (1995). Learner autonomy 4: The role of authentic texts. Dublin: Authentik Language Learning Resources Ltd.

McGrath, I. (2002). Materials evaluation and design for language teaching. Edinburgh: Edinburgh University Press.

Merriam, S. B., \& Caffarella, R. S. (1999). Learning in adulthood: A comprehensive guide. San Francisco: Jossey-Bass.

Mishan, F. (2005). Designing authenticity into language teaching materials. Bristol: Intellect.

Nunan, D. (1988). The learner-centered curriculum. Cambridge: Cambridge University Press. https://doi.org/10.1017/CBO9781139524506

Nunan, D. (1994). Task-based syllabus design: Selecting, grading and sequencing tasks. In G. Crookes \& S. Gass (eds.), Tasks in a Pedagogic Context: Integrating Theory and Practice (pp. 55-68). Clevedon, England: Multilingual Matters. 
Nunan, D. (2004). Task-based language teaching. Cambridge: Cambridge University Press. https://doi.org/10.1017/CBO9780511667336

Nuttall, C. (1996). Teaching reading skills in a foreign language. Oxford, Heinemann.

Peacock, M. (1997). The effect of authentic materials in the motivation of EFL learners. ELT Journal, 51, 2, 144-156. https://doi.org/10.1093/elt/51.2.144

Pennycook, A. (1997). Cultural alternatives and autonomy. In P. Benson \& P. Voller (eds.) Autonomy and Independence in Language Learning (pp. 35-53). London: Longman.

Perreault, H. R. (1999). Authentic activities for business education. Delta Pi Epsilon, 41(1), 35-41.

Potts, D. (2005). Pedagogy, purpose, and the second language learner in on-line communities. Canadian Modern Language Review, 62(1), 137-160. https://doi.org/10.3138/cmlr.62.1.137

Richards, J. C. (2001). Curriculum development in language teaching. Cambridge: Cambridge University Press. https://doi.org/10.1017/CBO9780511667220

Skehan, P. (1998b). Task-based instructions. Annual Review of Applied Linguistics 18, 268- 286. $10.1017 / \mathrm{s} 0267190500003585$

Swaffar, J. (1985). Reading authentic texts in a foreign language: A cognitive model. The Modern Language Journal, 69(1), 16-32. https://doi.org/10.1111/j.1540-4781.1985.tb02521.x

Tomlinson, B. (2003). Developing materials for language teaching. London: Continuum.

Van Lier, L. (1988). The classroom and the language learner: Ethnography and second language classroom research. New York: Longman.

Van Lier, L. (1996). Interaction in the language curriculum: Awareness, autonomy and authenticity. London: Longman.

Wallace, C. (1992). Reading. Oxford: Oxford University Press.

Wardman, C. (2009). Authentic materials: Are they as good as we think? MATSDA Folio, 13(2), 14-17.

Widdowson, H. (1978). Teaching language as communication. Oxford: Oxford University Press.

Widdowson, H. (1990). Aspects of language teaching. Oxford: Oxford University Press.

Wong, V., Kwok, P., \& Choi, N. (1995). The use of authentic materials at tertiary level. ELT Journal, 49(4), 318-322. https://doi.org/10.1093/elt/49.4.318

\section{Copyrights}

Copyright for this article is retained by the author(s), with first publication rights granted to the journal.

This is an open-access article distributed under the terms and conditions of the Creative Commons Attribution license (http://creativecommons.org/licenses/by/4.0/). 